\title{
Spiral aftereffect durations following awakening from REM sleep and non-REM sleep
}

\author{
P. LAVIE* and Z. GIORA \\ Tel Aviv University, Tel Aviv, Israel
}

\begin{abstract}
Nine Ss were awakened 2 min after the beginning of a REM period and 2 min after the beginning of a non-REM period (Stage 4), and were tested on a spiral aftereffect. The duration of the spiral aftereffect was found to be longer for the tests made following REM periods than for the tests made following non-REM periods. The results were interpreted to suggest a possible "carry over" effect from the particular sleep stage into the waking state.
\end{abstract}

The possible existence of a basic 24-h biological rhythm, on which the sleep cycle is superimposed, has stimulated a considerable amount of research in the last few years. The methods by which different researchers have tried to confirm the existence of a basic rest and activity cycle, as was proposed originally by Kleitman (1969), can be roughly divided into two categories: the direct method and the indirect method. The main goal of the "direct" researchers has been to show that the sleep cycle is a time-lock mechanism, independent of the night and continuous throughout the $24 \mathrm{~h}$. The sleep cycle has been observed during different times of day and night and under various conditions, such as naps, sensory deprivation, unusual schedules of sleep, and in Ss suffering from narcolepsy. Included in the indirect method were studies designed to try to prove the existence of a daily rhythm, with similar periodicity as the sleep cycle, and presumably with the same function. The daily rhythm was considered to be a daily representation of the basic cycle underlying the sleep cycle (Friedman \& Fisher, 1966; Oswald et al, 1970; Dement et al, 1972: Globus, 1966; Globus et al, 1972; Kripke et al, 1970; Sterman et al, 1970; Othmer et al, 1966; Webb \& Agnew, 1966).

Most of these studies conclude with remarks such as: "... the D state [another designation to the REM state] has essentially nothing to do with sleep itself, but rather it is only during sleep that the D state can be measured by current techniques. Thus, the characteristic Stage 1, the REMs, and the decreased muscle activity are not the essential process itself, but only signs by which the process can be recognized. Because of the ongoing state of the waking organism it would be extremely difficult to pick up such signs [Globus, 1966, p. 657; italics added]."

In light of such remarks, it seems surprising that only one study focused on wakefulness periods following awakenings from REM sleep and non-REM sleep (Fiss

*Peretz Lavie is presently at the University of Florida, Gainesville. Florida. Address reprint requests to: Peretz Lavie, 101 NASA Building, University of Florida, Gainesville, Florida 32601 . et al, 1966). It seems likely that these wakefulness periods would be less affected by the "on-going state of the waking organism," and qualitative differences between these periods may help to elaborate whether the sleep cycle continues "beyond" sleep. Fiss et al (1966) found indirect evidence that the REM state, or part of it, penetrates into wakefulness. Ss gave different responses to the Thematic Apperception Test upon awakening from REM sleep and non-REM sleep. The REM sleeper's responses were more bizzare and more "dream like."

In this study, a simple and quantifiable method, the spiral aftereffect (SAE) has been used in order to evaluate the possible continuation of the sleep cycle into wakefulness. Research has indicated that the duration of the SAE is influenced by two main factors: the persistence of the visual stimuli and the level of cortical arousability (Holland, 1964). It was suggested that, due to the high level of cortical arousability during REM sleep and the inhibition of cortical activity during non-REM sleep (Jouvet, 1968), the continuation of these states into wakefulness would lead to longer durations of the SAE following awakening from REM sleep than following awakening from non-REM sleep.

\section{METHOD}

\section{Subjects}

Nine naive Ss, six females and three males, aged 18-24 years, were tested. The Ss were asked to avoid alcohol, drugs, etc., during the day preceding the night the data were accumulated.

\section{Procedure}

Ss reported to the laboratory on the experimental night an hour before their usual bedtimes. Upon their arrival, they were fitted in the usual manner with electrodes for recording their EOG and their EEG (Rechtschaffen \& Kales, 1968).

After being connected to the polygraph, the $S$ s were given an explanation of the SAE phenomenon. They were then given an experience with the SAE to familiarize them with the phenomenon. Each $S$ was then tested five times on the SAE. The average score of the five trials was the score of the test. (The SAE apparatus was a remotely controlled rotary display with a constant speed of $60 \mathrm{rpm}$; it was located near the bed. It was activated for $30 \mathrm{sec}$. in a counterclockwise direction each time.) 
Table 1

Average Durations Ifade on Nine Ss for REM and

Non-REM Awakenings and Hakefulness (in Seconds)

\begin{tabular}{cccc}
\hline $\begin{array}{c}\text { Test } \\
\text { Condition }\end{array}$ & REM & $\begin{array}{c}\text { Non- } \\
\text { REMI }\end{array}$ & $\begin{array}{c}\text { Wake- } \\
\text { fulness }\end{array}$ \\
\hline$\overline{\mathrm{X}}$ & $1 \mathrm{S.2}$ & 10.6 & 12.8 \\
$\mathrm{~S}$ & $\overline{7.43}$ & 7.50 & 8.10 \\
\hline
\end{tabular}

Table 2

Analysis of Variance Performed on the Spiral Aftereffect Durations

\begin{tabular}{lrccc}
\hline Source of Variance & df & SS & MS & F \\
\hline Test Condition (T) & 2 & 36.34 & 18.17 & $5.32 *$ \\
Subjects (S) & 8 & 1376.2 & 172.025 & \\
TS & 16 & 54.57 & 3.41 & \\
Total & 26 & 1467.1 & & \\
\hline
\end{tabular}

${ }^{*} p<.05$

The Ss were instructed to report verbally when they stopped seeing the illusion. The duration of the ilusion was timed with a stopwatch. After the test. the Ss went to sleep. During the night. the Ss were awakened twice: first. $5 \mathrm{~min}$ after the beginning of the first or second REM period. and second. $5 \mathrm{~min}$ after the beginning of the non-REM sleep. State 4 . following REM 2 or REM 1. Criteria for identifying sleep stages were those described by Rechtschaffen and Kales 1968). The order of awakenings was balanced across nights in a systematic fashion: that is. if the first $S$ had the order of REM 1. non-REM 2. the second $S$ had the order of non-REM 1. REM 2. Assignment of Ss to these orders was done randomly. The Ss were awakened by being called by their first names. After $2 \mathrm{~min}$ for the $S$ to adapt to the light, the Ss were tested on the SAE in the same manner as they had been tested before sleep. The data were analyzed by an analysis of variance. repeated design.

\section{RESULTS}

The mean of the tests in the three conditions and the standard deviations are presented in Table 1. Eight of the Ss had higher SAE durations for REM awakening than for non-REM awakening. One $S$ showed the opposite effect. The ANOVA performed on the results is shown in Table 2. The duration of the SAE after awakening from REM sleep, after awakening from non-REM sleep. and before sleep differ significantly, $F(2,16)=5.32, p<.025$. The statistic suggested by Newman-Keuls (Winer. 1962) was used in order to test for differences among the three conditions. The durations of the SAE following awakening from REM sleep was found to be longer than the duration of the SAE following awakening from non-REM sleep, $t(16)=$ $2.98, \mathrm{p}<.01$. The wakefulness durations were found to be significantly longer than the non-REM durations, $t(16)=2.52 . p<.05$. No difference was found between the REM durations and the wakefulness durations, $t(16)<1$.

\section{DISCUSSION}

This study revesis differences in wakefulness periods following different phases of sleep as measured by the durations of the SAE.

These results suggest that a closer observation of wakefulness periods following different phases of sleep may be a fruitful method for exploring the consequences of such phases.

Moreover, to the extent to which we accept the interpretation that the duration of the SAE reflects cortical arousability and the interpretation of a higher level of cortical excitability during REM sleep than during non-REM sleep, the results suggest that the effects of REM sleep may penetrate into the waking state.

\section{REFERENCES}

Dement. W.. Kelley, J., Lauglin, E., Carpenter. S.. Simmons, J., Sidoric. K.. \& Lentz, R. Life on the basic rest activity cycle (BRAC): Sleep studies of a ninety minute day. Psychophysiology, 1972, 9, 139. (Abstract)

Fiss. H. Klein. G. S., \& Bekerat. E. Waking fantasis following interruption of two types of sleep. Archives of General Psychiatry. 1966. 14. 543-551.

Friedman. S., \& Fisher. C. On the presence of a rhythmic diurnal. oral instinctual drive cycle in man. Journal of the American Psychoanalytic Association, 1967, 15. 317.

Globus. G. Rapid eye movements in real time. Archives of General Psychiatry, 1966. 15. 654-659.

Globus. G., Drury. E.. Phoebus. E. \& Boyd. R. Ultradian rhythms in performance. Psychophysiology, 1972. 9. 132. (Abstract)

Holland, H. C. The spiral after effect. Oxford: Pergamon Press. 1964.

Jouvet, M. Mechanisms of paradoxical sleep: A neurophysiological approach. Research Publications of the Association for Research in Nervous \& Mental Disease. 1968 , 45.

Kleitman, N. Basic rest and activity cycle. Paper presented at the meeting of the Association for the Psychophysiological Study of Sleep, Boston, 1969.

Kripke, D. F.. Halberg. F.. Crowley. T. J.. \& Pegram, V. G. Liltradian rhythms in rhesus monkeys. Psychophysiology, 1970.7.307. (Abstract)

Oswald. J.. Merrington. J.. \& Lewis. H. Cyclical "on demand" oral intake by adults. Nature, 1970, 225. 959-960.

Othmer, E.. Hayden, M. P., \& Segelbaum, R. Encephalic cycles during sleep and wakefulness in humans, a 24-hour pattern. Science. 1969. 109.667-669.

Rechtschaffen, A., \& Kales, A. (Eds.). A mamual of standardized terminologi, techniques and scoring system for sleep stages of human subjects. Washington, D.C: U.S. Government Printing Office. 1968.

Sterman, M. B., Lucas, E. A., \& MacDonald. L. R. Periodicity within sleep and operant performance in the cat. Brain Research, 1972, 38, 327-341.

Webb, W. B., Agnew, H. W., \& Sternthal, H. Sleep during the early morning. Psychonomic Science. 1966, 6, 277-278.

Winer. B. J. Statistical principles in experimental design. New York: McGraw-Hill. 1962. 